\title{
Validation of MIPAS IMK/IAA methane profiles
}

\author{
A. Laeng ${ }^{1}$, J. Plieninger ${ }^{1}$, T. von Clarmann ${ }^{1}$, U. Grabowski ${ }^{1}$, G. Stiller ${ }^{1}$, E. Eckert ${ }^{1}$, N. Glatthor ${ }^{1}$, F. Haenel ${ }^{1}$, \\ S. Kellmann ${ }^{1}$, M. Kiefer ${ }^{1}$, A. Linden ${ }^{1}$, S. Lossow ${ }^{1}$, L. Deaver ${ }^{3}$, A. Engel ${ }^{2}$, M. Hervig ${ }^{3}$, I. Levin ${ }^{7}$, M. McHugh $^{3}$, \\ S. Noël ${ }^{4}$, G. Toon ${ }^{5}$, and K. Walker ${ }^{6}$ \\ ${ }^{1}$ Institut für Meteorologie und Klimaforschung, Karlsruhe Institute of Technology, Karlsruhe, Germany \\ ${ }^{2}$ Institut für Atmosphäre und Umwelt, University of Frankfurt, Frankfurt, Germany \\ ${ }^{3}$ GATS Inc, Driggs, Idaho, USA \\ ${ }^{4}$ Institut für Umweltphysik, University of Bremen, Bremen, Germany \\ ${ }^{5}$ Jet Propulsion Laboratory, California Institute of Technology, Pasadena, California, USA \\ ${ }^{6}$ Department of Physics, University of Toronto, Toronto, Ontario, Canada \\ ${ }^{7}$ Institut für Umweltphysik, Heidelberg University, Heidelberg, Germany
}

Correspondence to: A. Laeng (alexandra.laeng@kit.edu)

Received: 2 May 2015 - Published in Atmos. Meas. Tech. Discuss.: 4 June 2015

Revised: 16 November 2015 - Accepted: 23 November 2015 - Published: 16 December 2015

\begin{abstract}
The Michelson Interferometer for Passive Atmospheric Sounding (MIPAS) is an infrared (IR) limb emission spectrometer on the Envisat platform. It measures trace gas distributions during day and night, pole-to-pole, over an altitude range from 6 to $70 \mathrm{~km}$ in nominal mode and up to $170 \mathrm{~km}$ in special modes, depending on the measurement mode, producing more than 1000 profiles day $^{-1}$. We present the results of a validation study of methane, version V5R_CH4_222, retrieved with the IMK/IAA (Institut für Meteorologie und Klimaforschung, Karlsruhe/Instituto de Astrofisica de Andalucia, Grenada) MIPAS scientific level 2 processor. The level 1 spectra are provided by the ESA (European Space Agency) and version 5 was used. The time period covered is 2005-2012, which corresponds to the period when MIPAS measured trace gas distributions at a reduced spectral resolution of $0.0625 \mathrm{~cm}^{-1}$. The comparison with satellite instruments includes the Atmospheric Chemistry Experiment Fourier Transform Spectrometer (ACE-FTS), the HALogen Occultation Experiment (HALOE), the Solar Occultation For Ice Experiment (SOFIE) and the SCanning Imaging Absorption spectroMeter for Atmospheric CHartographY (SCIAMACHY). Furthermore, comparisons with MkIV balloon-borne solar occultation measurements and with air sampling measurements performed by the University of Frankfurt are presented. The validation activities include bias determination, assessment of stability, precision validation, analysis of histograms and comparison of correspond-
\end{abstract}

ing climatologies. Above $50 \mathrm{~km}$ altitude, MIPAS methane mixing ratios agree within $3 \%$ with ACE-FTS and SOFIE. Between 30 and $40 \mathrm{~km}$ an agreement within $3 \%$ with SCIAMACHY has been found. In the middle stratosphere, there is no clear indication of a MIPAS bias since comparisons with various instruments contradict each other. In the lower stratosphere (below $25 \mathrm{~km}$ ) MIPAS $\mathrm{CH}_{4}$ is biased high with respect to satellite instruments, and the most likely estimate of this bias is $14 \%$. However, in the comparison with $\mathrm{CH}_{4}$ data obtained from cryogenic whole-air sampler (cryosampler) measurements, there is no evidence of a high bias in MIPAS between 20 and $25 \mathrm{~km}$ altitude. Precision validation is performed on collocated MIPAS-MIPAS pairs and suggests a slight underestimation of its uncertainties by a factor of 1.2. No significant evidence of an instrumental drift has been found.

\section{Introduction}

Atmospheric methane $\left(\mathrm{CH}_{4}\right)$ is the third most important greenhouse gas, after water vapor and $\mathrm{CO}_{2}$. There is no significant methane source in the atmosphere. Instead, it is released at the surface into the troposphere by natural processes and anthropogenic activity. Therefore, the vertical distribution of $\mathrm{CH}_{4}$ in the atmosphere is determined by the balance between the transport of methane upward from the sur- 
face and its chemical destruction. The chemical lifetime of methane in the troposphere is $8-10$ years, which is sufficiently long for $\mathrm{CH}_{4}$ to be transported from the troposphere into the stratosphere. In the stratosphere, the chemical lifetime of methane is of the same order of magnitude as the timescale of transport. This implies that throughout the atmosphere, the morphology of methane is determined mostly by dynamical processes, which makes it an excellent tracer to study transport processes (Brasseur and Solomon, 2005).

A common destruction mechanism for methane in the stratosphere and the troposphere is the temperaturedependent reaction with $\mathrm{OH}$, which forms the methyl radical $\mathrm{CH}_{3}$ and water vapor $\mathrm{H}_{2} \mathrm{O}$. In the troposphere, the oxidation scheme of methane starts with the reaction with $\mathrm{OH}$, which ultimately produces $\mathrm{CO}_{2}$. An important intermediate product in the decomposition of $\mathrm{CH}_{4}$ is formaldehyde $\mathrm{H}_{2} \mathrm{CO}$. Additional products of methane oxidation in the troposphere are $\mathrm{CO}$, and, in the presence of elevated concentrations of $\mathrm{NO}_{x}$, ozone. In the stratosphere, methane is oxidized, which, after a series of reactions, results in the production of water vapor and molecular hydrogen (Brasseur and Solomon, 2005). Additionally, through the reactions with lowly abundant O (1-D) or $\mathrm{Cl}$ atoms, $\mathrm{CH}_{3}$ and $\mathrm{OH}$ or $\mathrm{HCl}$ are formed, which makes methane a sink for chlorine atoms in the stratosphere.

In the troposphere, methane is well mixed and its volume mixing ratio (vmr) is quite uniform. Due to larger sources of methane in the Northern Hemisphere, an interhemispheric gradient can be observed, with Northern Hemisphere (NH) values being $\sim 10 \%$ higher (National Oceanic and Atmospheric Administration, NOAA; Dlugokencky et al., 2009), and this hemispheric asymmetry increases with time in 1992-2004 (Youn et al., 2006). There is also a distinct seasonal variation in methane abundance: larger sources and stronger chemical loss in warmer months lead to the largest concentrations in local winter and the lowest concentrations in local summer. The amplitude of the seasonal cycle is larger in the northern high latitudes, diminishing towards the equator. In the Southern Hemisphere (SH) the amplitude of the seasonal cycle of methane is quite constant with latitude and is smaller than in the NH (Brasseur and Solomon, 2005; National Oceanic and Atmospheric Administration, NOAA).

The Michelson Interferometer for Passive Atmospheric Sounding (MIPAS) is a high-resolution limb emission Fourier transform spectrometer designed to measure trace gas distributions from the upper troposphere to the mesosphere at global coverage during day and night (Fischer et al., 2008). From July 2002 to March 2004, the MIPAS instrument took measurements with a maximum optical path difference of $20 \mathrm{~cm}$; this corresponds to a high theoretical spectral resolution (HR) of $0.025 \mathrm{~cm}^{-1}$. Due to problems with the slide system of the interferometer mirror, very few measurements were performed in April-December 2004. MIPAS resumed the regular observations in January 2005 with an optical path difference (OPD) of $8 \mathrm{~cm}$, which corresponds to a reduced theoretical spectral resolution (RR) of $0.0625 \mathrm{~cm}^{-1}$.
Spectral resolutions of MIPAS measurements, theoretical, apodized and real, are summarized in the Table 1. MIPAS reduced-resolution nominal-mode data are sampled along the orbit every $410 \mathrm{~km}$, and a vertical profile contains information from up to 27 tangent altitudes between 6 and $70 \mathrm{~km}$ height.

Four MIPAS level 2 processors exist; each one has its own methane product. A homogenized description of the four processors and extensive comparison of their ozone products is given in Laeng et al. (2015). In Raspollini et al. (2014), among other species, methane from the ESA (European Space Agency) processor is compared with the three other products. All four products suffer from a positive bias at heights below $25 \mathrm{~km}$.

The Institut für Meteorologie und Klimaforschung (IMK) operates a scientific data processor (von Clarmann et al., 2003) in cooperation with Instituto de Astrofisica de Andalucia (IAA) which relies on ESA level 1B spectra. The MIPAS IMK/IAA methane data product covers mixing ratio profiles of the period 2002-2004 when MIPAS operated in its original high spectral resolution mode (Glatthor et al., 2005), as well as data from 2002 to 2004 when MIPAS measured at reduced spectral resolution (Chauhan et al., 2009; von Clarmann et al., 2009b). This paper reports the validation of the methane data retrieved from reduced spectral resolution measurements in nominal mode, which is version number V5R_CH4_222. The version of level 1 spectra is V5R. The analysis is limited on the reduced-resolution measurements only because the corresponding baseline was developed for reduced resolution only. Detailed descriptions of the inversion algorithm used by the MIPAS IMK/IAA scientific retrieval processor can be found in von Clarmann et al. (2003), von Clarmann et al. (2009b) and Laeng et al. (2015). Its first application to stratospheric $\mathrm{CH}_{4}$ is documented in Glatthor et al. (2005). The $\mathrm{CH}_{4}$ MIPAS product from the IMK/IAA Scientific Processor, together with 22 others species retrieved from MIPAS spectra, is publicly available from the processor group page, https://www.imk-asf.kit.edu/english/308.php.

Figure 1 shows the temporal evolution of the latitudinal distribution of $\mathrm{CH}_{4} \mathrm{vmrs}$ in ppmv at $12 \mathrm{~km}$ as seen by MIPAS in 2002-2004.

IMK/IAA MIPAS products are characterized by uncertainty estimates, as well as vertical averaging kernels. The latter are used to estimate the altitude resolution of the retrievals. In addition, the horizontal smoothing information is calculated for sample cases on the basis of the two-dimensional averaging kernels, computed from twodimensional Jacobians (von Clarmann et al., 2009a). The random error covariance matrices of the retrieved quantities are provided. The vertical resolution of a typical MIPAS IMK/IAA methane retrieval, derived from the full width at half maximum (FWHM) of the rows of the averaging kernel matrix, varies between 2 and $5 \mathrm{~km}$, as seen in Fig. 2 . 
Table 1. Optical path differences and spectral resolutions of MIPAS measurements.

\begin{tabular}{lllll}
\hline Period & OPD & Theoretical spectral resolution & Apodized spectral resolution & Real spectral resolution \\
\hline HR (2002-2004) & $20 \mathrm{~cm}$ & $0.025 \mathrm{~cm}^{-1}$ & $0.05 \mathrm{~cm}^{-1}$ & $0.035 \mathrm{~cm}^{-1}$ \\
RR (2002-2004) & $8 \mathrm{~cm}$ & $0.0625 \mathrm{~cm}^{-1}$ & $0.121 \mathrm{~cm}^{-1}$ & $0.0875 \mathrm{~cm}^{-1}$ \\
\hline
\end{tabular}

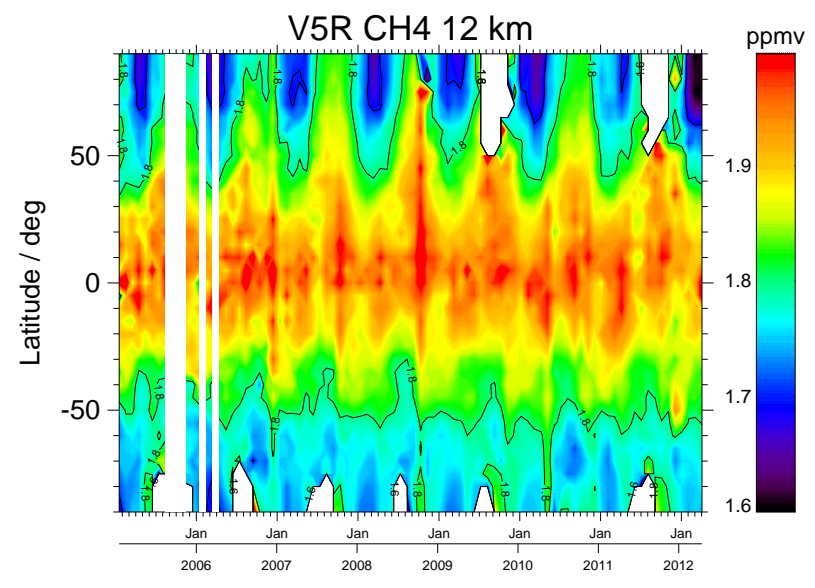

Figure 1. Temporal evolution of latitudinal distribution of $\mathrm{CH}_{4}$ vmrs at $12 \mathrm{~km}$ as seen by MIPAS.
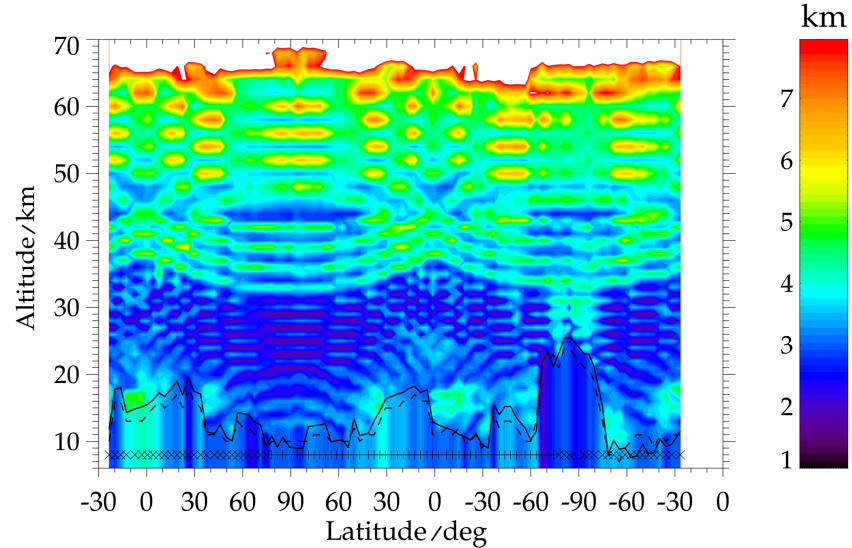

Figure 2. Vertical resolution of $\mathrm{CH}_{4}$ profiles along one orbit. The oscillation nature of the altitude resolution is caused by the fact that the altitude resolution is better at a tangent altitude than between two adjacent tangent altitudes.

\section{Reference instruments and comparison methodology}

The reference data sets and their main characteristics are presented in Table 2. All reference data sets except for the cryosampler measurements are publicly available. The cryosampler measurements were provided by A. Engel from the University of Frankfurt. The MIPAS reducedresolution period covers the years 2002-2004. During this time, five other satellite instruments measured the vertical profiles of methane: the Atmospheric Chemistry Ex- periment Fourier Transform Spectrometer (ACE-FTS), the HALogen Occultation Experiment (HALOE), the SCanning Imaging Absorption spectroMeter for Atmospheric CHartographY (SCIAMACHY), the Solar Occultation For Ice Experiment (SOFIE), and the Tropospheric Emission Spectrometer (TES); see, for example, the list of trace gases measured by atmospheric sensors collected on the Belgian Institute for Space Aeronomy (BIRA) website (Network for the Detection of Atmospheric Composition Change , NDACC). The comparison with four of these instruments is presented here. TES data were not used because the coarse vertical resolution of TES makes it less suited for validation of a limb data set. Similarly, no ground-based Fourier transform infrared measurements were used because of their coarse $(10 \mathrm{~km})$ vertical resolution. Instead, we have used methane vertical profiles from two balloon-borne instruments: the MkIV solar occultation interferometer and the cryogenic whole-air sampler, called a cryosampler, operated by the University of Frankfurt.

The MkIV interferometer from Jet Propulsion Laboratory (JPL) is a high-resolution solar absorption spectrometer which is deployed on stratospheric balloon platforms with a typical float altitude of $37 \mathrm{~km}$ (Toon, 1991). MkIV measured three methane vmr vertical profiles during the MIPAS reduced-resolution period, all of them from flights launched at $\left(35^{\circ} \mathrm{N}, 100^{\circ} \mathrm{W}\right)$. The data set is provided on a $1 \mathrm{~km}$ height grid between 10 and $40 \mathrm{~km}$. The vertical resolution of the MkIV balloon profiles varies between 2 and $4 \mathrm{~km}$.

The cryosampler instrument collects high-volume wholeair samples in stainless containers, and freeze out the air by means of liquid neon. After the flight, the air is left to evaporate which provides high-pressure whole-air samples from different altitudes. The species $\mathrm{CH}_{4}$ is analyzed at Heidelberg University using a gas chromatograph with a flame ionization detector (Hammer et al., 2008). The error provided by $\mathrm{CH}_{4}$ cryosampler data is $3 \mathrm{ppbv}$ or $0.2 \%$, whatever is larger.

The choice of the collocation criteria was a result of the tradeoff between the collocations being as close as possible and the resulting sample being sufficiently large, at least a few hundreds measurements, distributed homogenously over the measured part of the globe. For ACE-FTS, half of the measurements lie at latitudes over $60^{\circ}$. Thus the collocation criteria of $9 \mathrm{~h}$ and $800 \mathrm{~km}$ have been chosen. For SCIAMACHY and SOFIE, which have a denser sampling pattern, this was tightened to $5 \mathrm{~h}$ and $500 \mathrm{~km}$. For HALOE, whose time overlap with the MIPAS reduced-resolution period is less than 8 months, the criteria were relaxed to $24 \mathrm{~h}$ and 
Table 2. Reference data sets.

\begin{tabular}{|c|c|c|c|c|c|c|c|c|}
\hline $\begin{array}{l}\text { Reference instrument/ } \\
\text { source }\end{array}$ & Version & Viewing geometry & Height range & Time overlap & Collocation criteria & $\begin{array}{l}\text { Number of } \\
\text { matches }\end{array}$ & Reference & Recent validation \\
\hline $\begin{array}{l}\text { ACE-FTS http: } \\
\text { //www.ace.uwaterloo. } \\
\text { ca/data.html }\end{array}$ & $\mathrm{v} 3.5$ & solar occultation & $10-70 \mathrm{~km}$ & $2005-2012$ & $9 \mathrm{~h}-800 \mathrm{~km}$ & 14200 & Boone et al. (2013) & Waymark et al. (2013) \\
\hline $\begin{array}{l}\text { HALOE http: } \\
\text { //haloe.gats-inc.com/ } \\
\text { download/index.php }\end{array}$ & v19 & solar occultation & $12-70 \mathrm{~km}$ & Jan-Aug 2005 & $24 \mathrm{~h}-1000 \mathrm{~km}$ & 783 & Russell III et al. (1993) & Park et al. (1996) \\
\hline $\begin{array}{l}\text { SCIAMACHY http: } \\
\text { //www.iup.uni-bremen. } \\
\text { de/ noel/Data/ONPD/ }\end{array}$ & v3.3.6 & solar occultation & $20-40 \mathrm{~km}$ & $2005-2010$ & $5 \mathrm{~h}-500 \mathrm{~km}$ & 5636 & Noël et al. (2011) & Noël et al. (2011) \\
\hline $\begin{array}{l}\text { SOFIE http: } \\
\text { //sofie.gats-inc.com/ } \\
\text { sofie/index.php }\end{array}$ & v1.2 & solar occultation & $45-70 \mathrm{~km}$ & 2007-2012 & $5 \mathrm{~h}-500 \mathrm{~km}$ & 29124 & Gordley et al. (2009) & \\
\hline $\begin{array}{l}\text { MkIV http: } \\
\text { //mark4sun.jpl.nasa. } \\
\text { gov/m4data.html }\end{array}$ & $\mathrm{n} / \mathrm{a}$ & solar occultation & $10-40 \mathrm{~km}$ & $2005-2007$ & $24 \mathrm{~h}-1000 \mathrm{~km}$ & 3 & Toon (1991) & Toon et al. (1999) \\
\hline $\begin{array}{l}\text { Cryosampler } \\
\text { an.engel@iau.uni- } \\
\text { frankfurt.de }\end{array}$ & $\mathrm{n} / \mathrm{a}$ & $\mathrm{n} / \mathrm{a}$ & $10-35 \mathrm{~km}$ & 2005-2009 & $24 \mathrm{~h}-1000 \mathrm{~km}$ & 58 & $\begin{array}{l}\text { Engel et al. (1997); } \\
\text { Levin et al. (1999); } \\
\text { Hammer et al. (2008) }\end{array}$ & \\
\hline
\end{tabular}
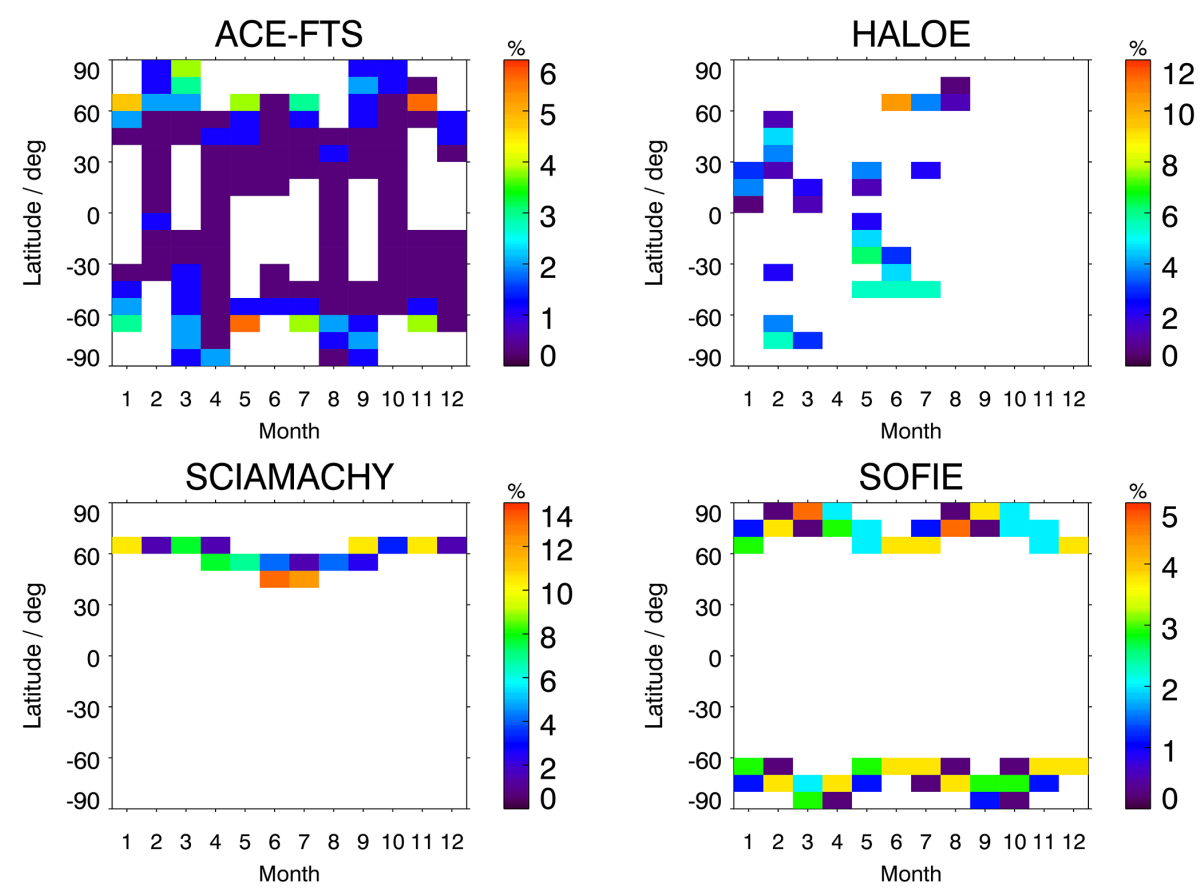

Figure 3. Monthly latitudinal distributions of collocated measurements of MIPAS with reference instruments, in percent.

$1000 \mathrm{~km}$, which remains acceptable in terms of the physics of $\mathrm{CH}_{4}$ in the stratosphere. These choices led to the number of matched pairs as listed in Table 2. Figure 3 shows the latitudinal distributions over months of collocated measurements of MIPAS with each satellite reference instrument. Figure 3 suggests that the correlative measurements are available primarily in regions where small-scale natural variability is an issue. An assessment of the precision of the pairs between MIPAS and each reference instrument is usually done by comparing the standard deviation of the differences with the combined estimated random error (von Clarmann, 2006). Here in all cases except HALOE, most collocations are con- centrated at high latitudes, where the atmospheric variability contribution into the standard deviation of the differences is significant. To assess the quality of uncertainty estimates of MIPAS $\mathrm{CH}_{4}$ data, the structure functions as described in Laeng et al. (2015) will be constructed in Sect. 5. The matched pairs were chosen in such a way that none of the MIPAS (or reference instrument) measurements participated in two pairs. Such a choice reduces the number of matches, but produces pairs that are independent. For MkIV and cryosampler measurements, the collocation criteria were also relaxed and chosen to be $24 \mathrm{~h}$ and $1000 \mathrm{~km}$. In cases where no MIPAS data were available around the flight within the colloca- 
tion criteria, zonal means of MIPAS data for the corresponding month, season and latitude range were compared with the reference instrument profiles.

Cryosampler measurements do not provide continuous profiles but a series of independent point measurements. This means that not even smeared information about the atmospheric state between two sampling points is available. Thus no regridding has been performed and no averaging kernels applied; instead, these data have been used as they are and on the height where they were measured. The cryosampler measurements are taken at $10-30 \mathrm{~km}$ height, with steps from 1 to $3 \mathrm{~km}$.

All profiles from the reference instruments that provide continuous vertical profiles of methane, satellite-borne and MkIV, were interpolated to the MIPAS grid for intercomparison. Rodgers and Connor (1999) suggest application of averaging kernels of the poorer resolved profiles to the better resolved profiles during the regridding of atmospheric profiles. However, for all satellite or MkIV comparison instruments, the vertical resolution of typical MIPAS IMK/IAA methane profiles differs from the vertical resolution of reference instrument profiles by less than a factor of 2-2.5 and often is close to 1 . Thus the application of averaging kernels appears unnecessary. To be on the safe side, sensitivity studies were performed to assess the impact of the application of the averaging kernels; this was done for all reference instruments providing continuous profiles of methane, i.e., all satellite instruments and MkIV. When no averaging kernels were available for the coarser resolved reference instrument, the smoothing was done with a Gaussian filter of corresponding width. Application of the averaging kernels changed the significant parts of the profiles by less than $2 \%$. Hence, the differences in vertical resolution were chosen to be neglected and no averaging kernels were applied.

\section{Bias assessment}

\subsection{Comparison with satellite reference instruments}

Figure 4 represents the percentage bias of MIPAS $\mathrm{CH}_{4}$ retrievals with respect to the satellite reference instruments. We should keep in mind that the percentage bias is tricky to interpret when the reference values are low, which is the case for methane at the heights above $40-45 \mathrm{~km}$. The patterns of comparisons with ACE-FTS and HALOE are quite similar at heights below $25 \mathrm{~km}$, where MIPAS has a known high bias. At the same heights, SCIAMACHY has a known low bias, which explains the rightward position of the green curve at the plot.

The agreement with ACE-FTS at $20-65 \mathrm{~km}$ height is within $12 \%$, while in the lower stratosphere MIPAS vmrs are consistently higher than those of ACE-FTS. The largest bias found is $15 \%$ at $17 \mathrm{~km}$ altitude. A secondary maximum of the differences is found at $38 \mathrm{~km}$ altitude, where MIPAS

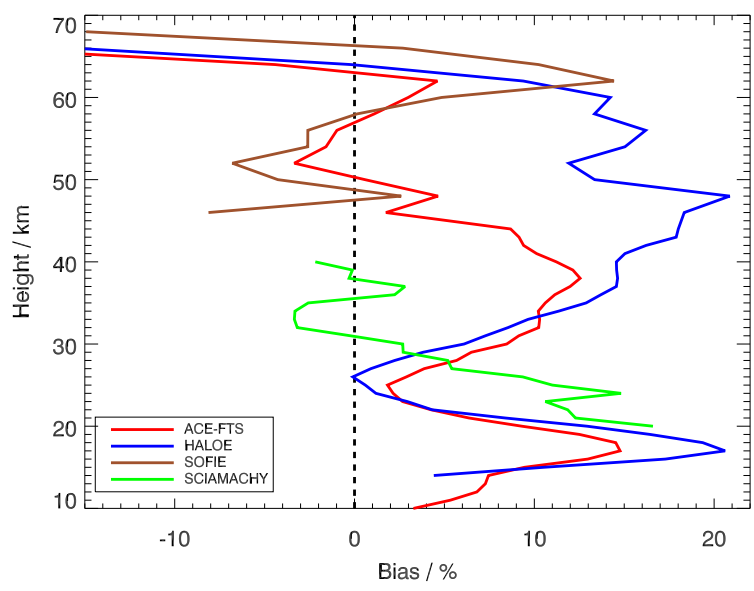

Figure 4. Bias estimation of MIPAS methane retrievals with respect to satellite reference instruments. The quantity shown is the mean estimate over all latitudes of $\frac{\text { MIPAS-REF }}{\mathrm{REF}} \times 100 \%$.

methane mixing ratios are higher by $12 \%$. The standard deviations of methane profiles from MIPAS and ACE-FTS in different seasons were studied. They have a pronounced maximum (up to $0.4 \mathrm{ppmv}$ ) at about $30 \mathrm{~km}$ altitude in fall, winter and spring, when the polar vortex is formed, persists and breaks down, respectively, which causes enhanced variability. One might speculate that different viewing geometries (with a larger north-south component for MIPAS and a larger east-west component for ACE-FTS) or different sensitivity to temperature variations along the line of sight might turn the enhanced random variability into a bias. The reduced variability actually leads to a smaller bias between MIPAS and ACE-FTS. In summer, when the meteorological situation in the stratosphere is quite calm, no such enhanced variability is observed. Another region of enhanced variability is the lowermost altitudes: the large variability there is attributed to tropopause height fluctuations.

Between 30 and $40 \mathrm{~km}$ altitude, the agreement between the global mean MIPAS and SCIAMACHY $\mathrm{CH}_{4}$ profiles is within $3 \%$. Below this altitude, MIPAS methane mixing ratios are higher than those of SCIAMACHY. The largest bias found is $17 \%$ at the lowest SCIAMACHY altitude, $20 \mathrm{~km}$.

HALOE data are considered as a reference in the atmospheric science community and have been extensively used for scientific analysis (Ruth et al., 1997; Randel et al., 1998, 1999; Gray and Russell Jr., 1999; Shu et al., 2013). Unfortunately the time overlap between MIPAS reduced-resolution period and HALOE operations is only 8 months, during which there were gaps in the MIPAS data. Even after relaxing the collocation criteria to $24 \mathrm{~h}$ and $1000 \mathrm{~km}$, only 783 independent matched pairs were found. The blue curve on Fig. 4 exposes the agreement within $10 \%$ of MIPAS and HALOE at $20-30 \mathrm{~km}$. Over almost the whole height range, the bias does not change sign and stays positive. Below $25 \mathrm{~km}$, the 

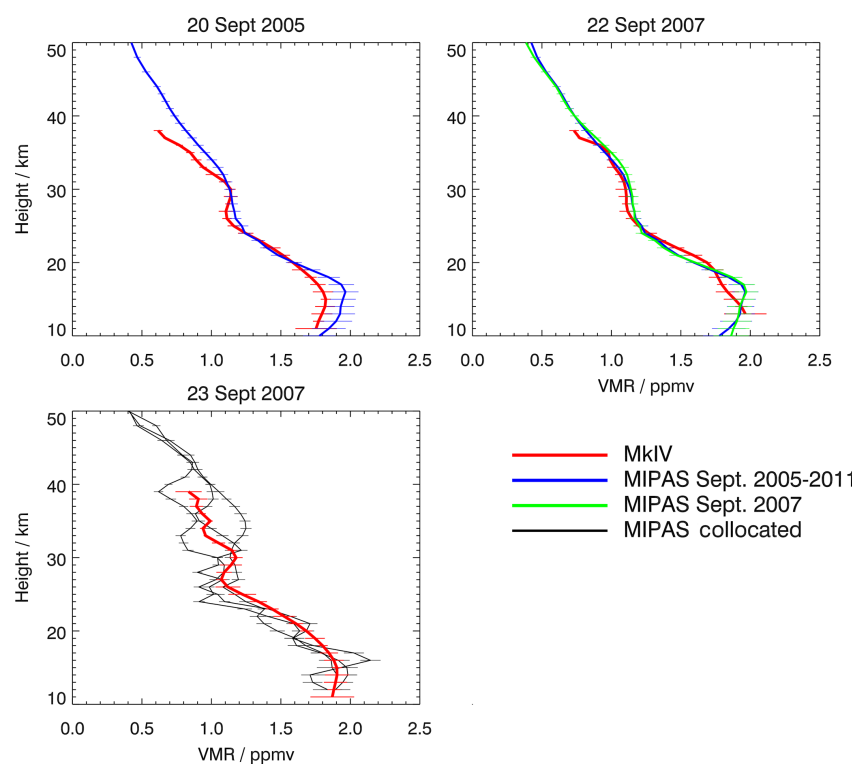

Figure 5. MkIV profiles and MIPAS CH4 vmr vertical profiles - collocated profiles when they exist, otherwise mean profiles in September 2007 and September of $2005-2011$ in the $30^{\circ}-40^{\circ} \mathrm{N}$ latitude band where the three balloon flights took place.

high bias of MIPAS methane is confirmed. Largest mean relative differences are about $20 \%$.

At the heights between 45 and $60 \mathrm{~km}$, the agreement between MIPAS and SOFIE is within $8 \%$. The maximum differences of $15 \%$ are observed at $63 \mathrm{~km}$. Let us recall that the relative differences become difficult to interpret when the reference values are getting small. This is particularly true for SOFIE whose delivered methane profiles start at $45 \mathrm{~km}$ height.

\subsection{Comparison with MkIV balloon interferometer profiles}

Figure 5 presents the three MkIV balloon profiles recorded within the MIPAS reduced-resolution period. The first two MkIV profiles, from 20 September 2005 and 22 September 2007, were measured when MIPAS was temporary inactive and no matches were found within $24 \mathrm{~h}$ and $1000 \mathrm{~km}$. The MkIV profiles were hence compared to the monthly (September) and seasonal (September-October-November, SON) means of MIPAS at $30^{\circ}-40^{\circ} \mathrm{N}$ latitudes. For the profile from 20 September 2005 , the agreement is very good from 20 to $24 \mathrm{~km}$ and 28 to $31 \mathrm{~km}$, while a positive MIPAS bias in the order of 0.2 ppmv is present at $12-20$ and 31$37 \mathrm{~km}$ heights. For the profile from the sunset of 22 September 2007 , the agreement is very good at $23-36 \mathrm{~km}$, while a positive MIPAS bias in the order of $0.1 \mathrm{ppmv}$ is present at $14-18 \mathrm{~km}$ heights and a negative MIPAS bias of the same order is present at $18-23 \mathrm{~km}$ heights.
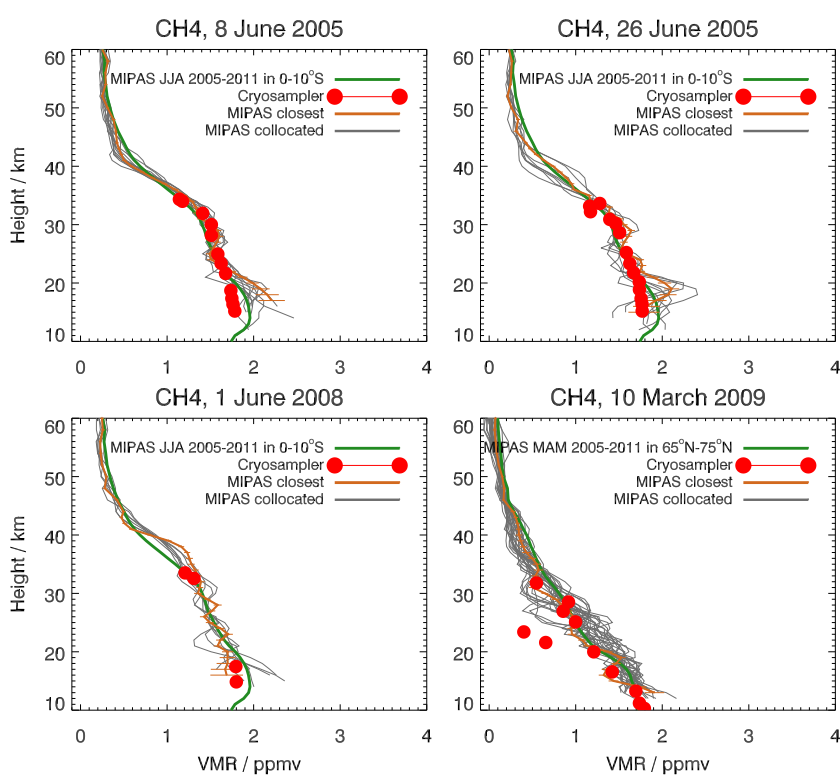

Figure 6. Four cryosampler profiles and MIPAS $\mathrm{CH} 4$ vmr profiles - collocated, monthly and seasonal means in corresponding latitude bands. JJA stands for June-July-August; MAM stands for MarchApril-May.

For the profile from the sunrise of 23 September 2007, three collocated MIPAS profiles were found (gray lines). Maximum deviation of those three profiles from the MkIV profile is 0.3 ppmv. Note that the positive MIPAS bias below $25 \mathrm{~km}$, shown in the comparison with satellite instruments, is less pronounced in the comparison with MkIV profiles.

\subsection{Comparison with cryosampler profiles}

In Fig. 6 the comparison of MIPAS methane and the cryosampler measurements is shown. Besides the closest MIPAS profile (orange line) and the set of all MIPAS profiles meeting the coincidence criteria (gray lines; mean value: green line) also the climatological mean of the season and latitude is shown (green line). For the first two flights (upper panel of Fig. 6) the agreement between 23 and $32 \mathrm{~km}$ heights is excellent. As expected, the individual collocated profiles agree better than the corresponding means. Below $20 \mathrm{~km}$, the high MIPAS bias of about $0.2 \mathrm{ppmv}$ (less than $10 \%$ ) is present. Unlike in the satellite-satellite comparisons, at 20 $25 \mathrm{~km}$ height, the MIPAS measurements agree very well with the cryosampler measurements.

The third flight (bottom left panel of Fig. 6) of the cryosampler instrument gave rise to only four measurements, none of which is situated between 18 and $32 \mathrm{~km}$. The two measurements above $32 \mathrm{~km}$ agree well with MIPAS. The two data points below $18 \mathrm{~km}$ reveal that the MIPAS $\mathrm{CH}_{4} \mathrm{vmr}$ is larger by 0.1 and 0.2 ppmv than the cryosampler measurement. 


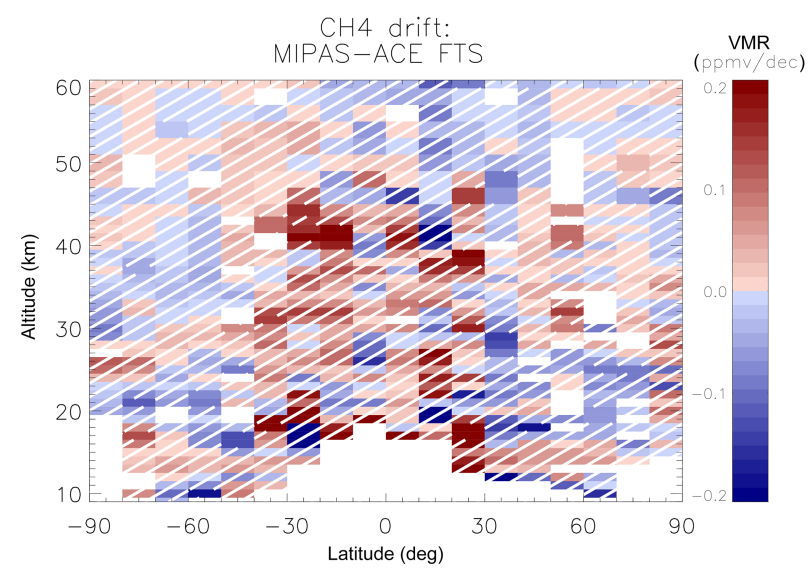

Figure 7. Drifts of MIPAS with respect to ACE-FTS methane measurements as a function of height and latitude. The bins where the significance is less than $2 \sigma$ are hatched.

The last flight (bottom right panel of Fig. 6) stands out by a pronounced local $\mathrm{CH}_{4}$ minimum in the cryosampler data at approximately 22 and $24 \mathrm{~km}$, which is also partly reproduced by the MIPAS data. At the other altitudes, the cryosampler profile agrees reasonably well with both the collocated and the zonal mean MIPAS profiles. This suggests that atmospheric variability on small spatial and temporal scales is much smaller there; thus the different sampling characteristics have less impact on the comparison. Below $20 \mathrm{~km}$ the tendency of MIPAS towards higher $\mathrm{CH}_{4}$ mixing ratios is confirmed also here. The amplitude of the bias is smaller for cryosampler than for satellite comparisons: $10 \%$ for the cryosampler, compared to $16-17 \%$ for satellites. This comparison of the bias estimations from different type of reference instruments should however be treated with caution because the samples on which the comparisons are made are quite different: three isolated profiles as opposed to hundreds or thousands of matched pairs. However, while the small number of coincident measurements is a limitation of the comparison of MIPAS with the cryosampler measurements, the scientific merit of this data set is the high precision of the cryosampler data.

\section{Stability}

Based on the monthly distribution of coincident measurements (see Fig. 3) and altitude coverage (see Table 2), only with ACE-FTS was there a chance to analyze the temporal evolution of the bias as a measure of instrument stability. Note however, that the stability of ACE-FTS itself has not yet been investigated. As to MIPAS, a recent study by Kiefer et al. (2013) showed that the way the detector nonlinearity is corrected in level 1B spectra (up to version 5, used for the present MIPAS data set) could be a potential source for the drift in MIPAS data products.
To assess the temporal evolution of the bias of MIPAS with respect to ACE-FTS (i.e., drifts), the monthly means of differences MIPAS-ACE were calculated, then the multilinear parametric trend model from von Clarmann et al. (2010) with extensions by Stiller et al. (2012) and Eckert et al. (2014) was applied. Figure 7 shows the values of the linear term of the drifts of MIPAS with respect to ACE-FTS as a function of height and latitude. Most of the obtained drift estimates on Fig. 7 are insignificant at the $2 \sigma$ level due to the small number of months for which collocations were found. Therefore, although a drift is to be expected due to theoretical considerations (Kiefer et al., 2013) and the analysis of other species (Eckert et al., 2014), we have not found any empirical evidence of a drift in MIPAS methane, using the available comparison data.

\section{Precision validation}

The uncertainty provided by a data set usually contains the random component of the error (random error). Validation of the random error is needed when the measurement uncertainty cannot be fully characterized or is based on assumptions. This is especially important for remote-sensing measurements, which use retrievals of atmospheric parameters by solving inverse problems. The random error of the remotesensing measurements is usually estimated via propagation of instrumental noise and uncertain randomly varying parameters through the inversion algorithm. These estimates can be imperfect due to incomplete forward models or retrieval approximations. For the MIPAS IMK/IAA $\mathrm{CH}_{4}$ data set, the uncertainties provided by the data set are composed of the measurement noise and randomly varying parameter uncertainties, i.e., parameter errors with a strong random component, such as the spectroscopic error, line of sight of the instrument, horizontal temperature gradient and instrument calibration error. In order to evaluate how realistic these uncertainty estimates are, one compares the square of the mean uncertainty $\sigma_{\text {random }}$ provided by the data set with the variance of a sample derived from the data set, performed in a region with low natural variability $\sigma_{\text {nat }}$ and converging/intersecting orbits. Polar summer measurements best met both criteria. While the direct comparison is often affected by natural variability within the collocation radius, the approach chosen here aims at solving this problem by statistically comparing the differences as a function of spatiotemporal distance. This approach was used in Sofieva et al. (2014) and Laeng et al. (2015) for the evaluation of the quality of uncertainty estimates provided by GOMOS (Global Ozone Monitoring by Occultation of Stars) and MIPAS ozone measurements.

We work with the sample which is composed of differences of collocated profiles, with converging collocation criteria. Then the variance $S_{\text {diff }}^{2}$ reflects the variability of (MIPAS-MIPAS) for collocated MIPAS pairs; the natural variability included in this variance is the small-scale natural 

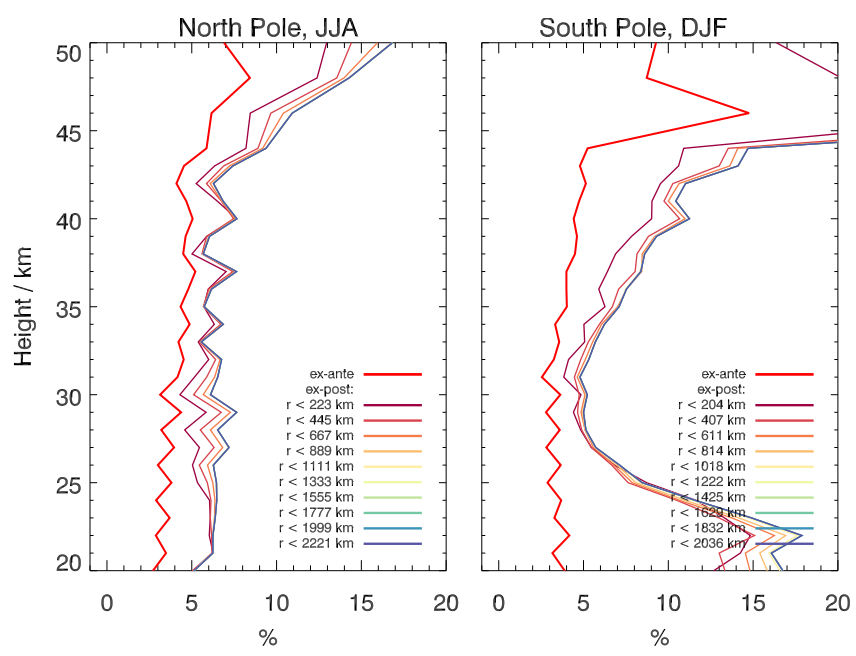

Figure 8. Structure functions of MIPAS IMK processor in two regions with low atmospheric variability: the North Pole in JuneJuly-August (JJA, left column) and the South Pole in DecemberJanuary-February (DJF, right column). The analysis was run on 430 pairs within $220 \mathrm{~km}, 7500$ pairs within $880 \mathrm{~km}$, going up to 12400 pairs within more than $2000 \mathrm{~km}$. The colored lines correspond to $S_{\text {diff }} / \sqrt{2}$ for converging distance $r$ between the air parcels, and the

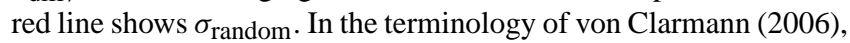
$S_{\text {diff }} / \sqrt{2}$ is the ex post error and $\sigma_{\text {random }}$ is the ex ante estimate of the error.

variability: $2 \sigma_{\text {random }}^{2}+\sigma_{\text {nat }}^{2}=S_{\text {diff. }}^{2}$. We expect that the smaller the separation distance, the smaller the discrepancy between $\sigma_{\text {random }}$ and $S_{\text {diff }} / \sqrt{2}$ is. In particular, when the separation distance tends to zero, $S_{\text {diff }} / \sqrt{2}$ should approach $\sigma_{\text {random }}$, if the latter is realistic (recall that the atmospheric variability in the selected regions is small). The parameter $S_{\text {diff }} / \sqrt{2}$ is a direct analogue of the integral of the structure function from the theory of random functions. More details can be found in Sofieva et al. (2014) and Laeng et al. (2015). In Fig. 8, we construct structure functions for MIPAS methane retrieval. The colored lines in Fig. 8 correspond to $S_{\text {diff }} / \sqrt{2}$ for converging distance $r$ between the air parcels, and the red line shows $\sigma_{\text {random. }}$. In the terminology of von Clarmann (2006), $S_{\text {diff }} / \sqrt{2}$ is the ex post estimate of the error and $\sigma_{\text {random }}$ is the ex ante estimate of the error. As observed in Fig. $8, S_{\text {diff }} / \sqrt{2}$ nicely converges with decreasing separation distance, but does not approach $\sigma_{\text {random }}$, the values on the limit curve of $S_{\text {diff }} / \sqrt{2}$ being approximatively 1.2 larger than $\sigma_{\text {random }}$ values. This indicates a slight (by a factor of about 1.2) underestimation of error estimates in $\mathrm{CH}_{4}$ MIPAS IMK/IAA retrievals.

\section{Climatology and histogram comparisons}

Figure 9 represents the temporal evolution of methane monthly zonal means of SCIAMACHY (top panel), MIPAS (middle panel) and the relative difference (bottom panel).

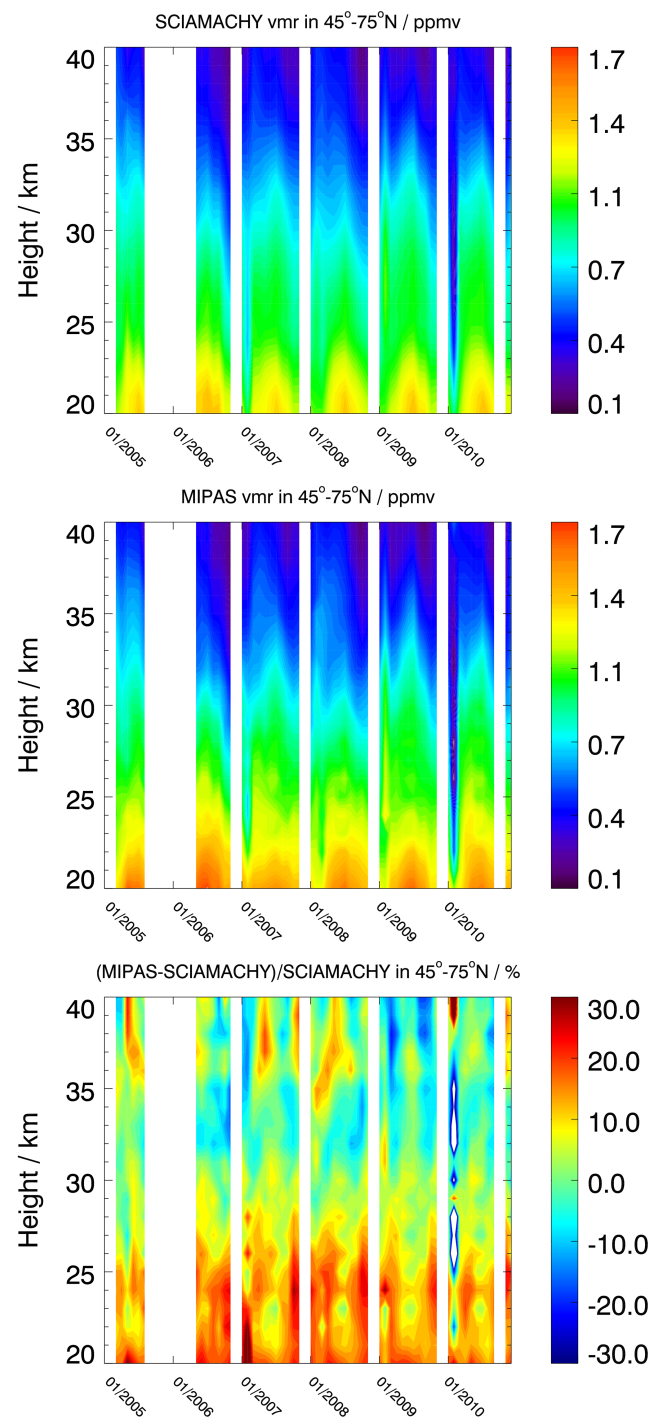

Figure 9. Monthly mean values of SCIAMACHY (top panel) and MIPAS (middle panel) and monthly means of differences (MIPASSCIAMACHY)/SCIAMACHY in percent (bottom panel) in 20052010.

The SCIAMACHY instrument was chosen for this study because of its best agreement in the stratosphere with MIPAS methane profiles. The comparison band $45^{\circ}-75^{\circ} \mathrm{N}$ is restricted by the band $50^{\circ}-70^{\circ} \mathrm{N}$ where SCIAMACHY measures in solar occultation mode, from which vertical profiles of methane are retrieved (Noël et al., 2011). As a dynamical tracer, $\mathrm{CH}_{4}$ is expected to follow the transport patterns. As one can see in Fig. 9, MIPAS and SCIAMACHY instruments see a similar morphology in the structure of atmospheric variation of methane, in particular a pronounced annual cycle. The strong red parts in the lower panel of Fig. 9 occur mostly in wintertime and are most probably due to the polar vortex edge, i.e., the studied air masses are not always comparable. 

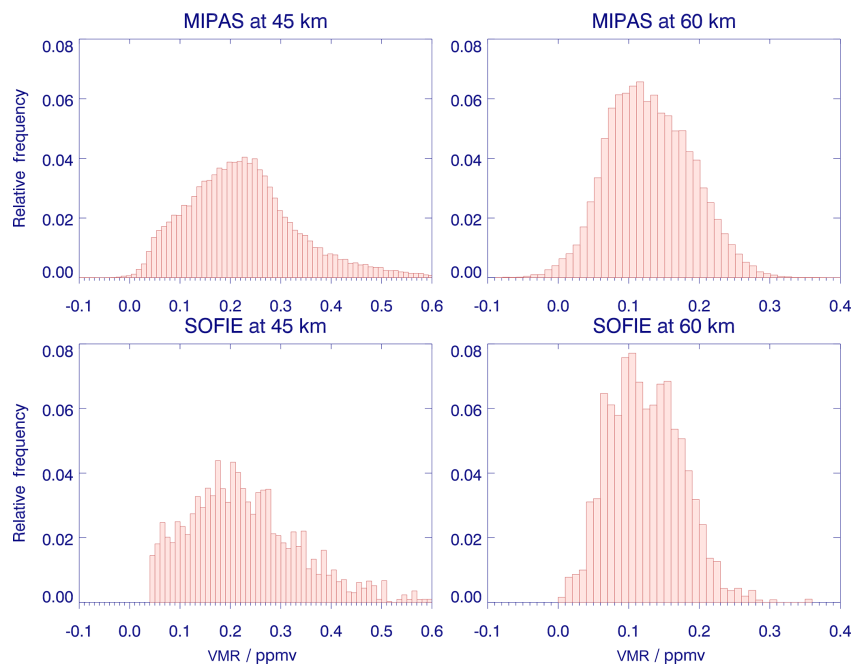

Figure 10. Relative frequency of vmr values of MIPAS (upper line) and SOFIE (bottom line) at $45 \mathrm{~km}$ (left column) and $60 \mathrm{~km}$ (right column).

Histograms of collocated MIPAS and SOFIE $\mathrm{CH}_{4}$ mixing ratios were compared for altitudes $45 \mathrm{~km}$ (Fig. 10, left panels) and $60 \mathrm{~km}$ (right panels). The corresponding MIPAS and SOFIE histograms agree with respect to the approximate position of the main mode, their approximate width and their skewness. The SOFIE histograms, however, present several secondary modes. Such a structure is not seen in any comparison of MIPAS with other instruments, which hints at some systematic or retrieval-related effect in the SOFIE methane retrievals, causing the numerous positive and negative outliers, e.g., turning points of "onion-peeling"-related profile oscillations (Goldman and Saunders, 1979). Thus these features provide no evidence of any spurious characteristics of the MIPAS data.

\section{Conclusions}

The MIPAS IMK V5R_CH4_222 data were compared to the data from four satellite instruments and two balloon-borne instruments. Precision validation was performed on collocated MIPAS-MIPAS pairs. MIPAS methane has a fairly realistic characterization of its random retrieval errors (a slight underestimation by about $20 \%$ ).

Although a drift is to be expected due to theoretical considerations (Kiefer et al., 2013) and the analysis of other species (Eckert et al., 2014), analysis performed on the only suitable comparison data, ACE-FTS, does not provide any empirical evidence of a drift in MIPAS methane.

The bias of MIPAS methane has been characterized. Below $20-25 \mathrm{~km}$, MIPAS methane is biased high. The magnitude of this bias cannot unambiguously be inferred from the comparisons because results are not fully consistent, but it varies between 0 and 20, and $14 \%$ seems to be its most likely value. Interestingly, contrary to the satellite intercomparisons, in the comparison with $\mathrm{CH}_{4}$ data obtained from cryosampler measurements, there is no evidence of a MIPAS high bias between 20 and $25 \mathrm{~km}$ altitude. In the middle stratosphere, the bias analysis is a little ambiguous but MIPAS seems to have a slight tendency towards higher values. In the upper stratosphere and above, excellent agreement with the other instruments is found, except for altitudes near $70 \mathrm{~km}$, at the upper end of the MIPAS profiles, where MIPAS tends towards lower values. A high bias in MIPAS methane in the lower stratosphere, with larger values, has also been reported for the operational MIPAS data product provided by the ESA (Payan et al., 2009). Necessary future activities consist of the investigation and tentative removal of this bias.

Acknowledgements. The first author is grateful to Viktoria Sofieva for numerous helpful conversations. This work was performed in the framework of the European Space Agency Climate Change Initiative Greenhouse Gases Project. MIPAS level 1 data are provided by the European Space Agency. The ACE mission is supported primarily by the Canadian Space Agency. Part of this research was performed at the Jet Propulsion Laboratory, California Institute of Technology, under contract with NASA. We thank the Columbia Scientific Balloon Facility (CSBF) for performing the launches of the JPL MkIV instrument.

We acknowledge support by Deutsche Forschungsgemeinschaft and Open Access Publishing Fund of Karlsruhe Institute of Technology.

The article processing charges for this open-access publication were covered by a Research Centre of the Helmholtz Association.

Edited by: E. Kyrölä

\section{References}

Boone, C. D., Walker, K. A., and Bernath, P. F.: Version 3 Retrievals for the Atmospheric Chemistry Experiment Fourier Transform Spectrometer (ACE-FTS), in: The Atmospheric Chemistry Experiment ACE at 10: A Solar Occultation Anthology, edited by Bernath, P. F., 103-127, A. Deepak Publishing, Hampton, Virginia, USA, 2013.

Brasseur, G. and Solomon, S.: Aeronomy of the Middle Atmosphere-Chemistry and Physics of the Stratosphere and Mesosphere, Atmospheric and Oceanographic Sciences Library 32, Springer, Dordrecht, the Netherlands, third edn., 2005.

Chauhan, S., Höpfner, M., Stiller, G. P., von Clarmann, T., Funke, B., Glatthor, N., Grabowski, U., Linden, A., Kellmann, S., Milz, M., Steck, T., Fischer, H., Froidevaux, L., Lambert, A., Santee, M. L., Schwartz, M., Read, W. G., and Livesey, N. J.: MIPAS reduced spectral resolution UTLS-1 mode measurements of temperature, $\mathrm{O}_{3}, \mathrm{HNO}_{3}, \mathrm{~N}_{2} \mathrm{O}, \mathrm{H}_{2} \mathrm{O}$ and relative humidity over ice: retrievals and comparison to MLS, Atmos. Meas. Tech., 2, 337353, doi:10.5194/amt-2-337-2009, 2009. 
Dlugokencky, E. J., Bruhwiler, L., White, J. W. C., Emmons, L. K., Novelli, P. C., Montzka, S. A., Masarie, K. A., Lang, P. M., Crotwell, A. M., Miller, J. B., and Gatti, L. V.: Observational constraints on recent increases in the atmospheric $\mathrm{CH}_{4}$ burden, Geophys. Res. Lett., 36, L18803, doi:10.1029/2009GL039780, 2009.

Eckert, E., von Clarmann, T., Kiefer, M., Stiller, G. P., Lossow, S., Glatthor, N., Degenstein, D. A., Froidevaux, L., GodinBeekmann, S., Leblanc, T., McDermid, S., Pastel, M., Steinbrecht, W., Swart, D. P. J., Walker, K. A., and Bernath, P. F.: Drift-corrected trends and periodic variations in MIPAS IMK/IAA ozone measurements, Atmos. Chem. Phys., 14, 25712589, doi:10.5194/acp-14-2571-2014, 2014.

Engel, A., Schmidt, U., and Stachnik, R. A.: Partitioning between Chlorine Reservoir Species deduced from Observations in the Arctic Winter stratosphere, J. Atmos. Chem., 27, 107-126, 1997.

Fischer, H., Birk, M., Blom, C., Carli, B., Carlotti, M., von Clarmann, T., Delbouille, L., Dudhia, A., Ehhalt, D., Endemann, M., Flaud, J. M., Gessner, R., Kleinert, A., Koopman, R., Langen, J., López-Puertas, M., Mosner, P., Nett, H., Oelhaf, H., Perron, G., Remedios, J., Ridolfi, M., Stiller, G., and Zander, R.: MIPAS: an instrument for atmospheric and climate research, Atmos. Chem. Phys., 8, 2151-2188, doi:10.5194/acp-8-2151-2008, 2008.

Glatthor, N., von Clarmann, T., Fischer, H., Funke, B., Grabowski, U., Höpfner, M., Kellmann, S., Kiefer, M., Linden, A., Milz, M., Steck, T., Stiller, G. P., Mengistu Tsidu, G., and Wang, D. Y.: Mixing processes during the Antarctic vortex split in September/October 2002 as inferred from source gas and ozone distributions from ENVISAT-MIPAS, J. Atmos. Sci., 62, 787-800, 2005.

Goldman, A. and Saunders, R. S.: Analysis of Atmospheric Infrared Spectra for Altitude Distribution of Atmospheric Trace Constituents - I. Method of Analysis, J. Quant. Spectrosc. Radiat. Transfer, 21, 155-161, 1979.

Gordley, L. L., Hervig, M. E., Fish, C., Russell, J. M., Bailey, S., Cook, J., Hansen, S., Shumway, A., Paxton, G., Deaver, L., Marshall, T., Burton, J., Magill, B., Brown, C., Thompson, E., and Kemp, J.: The solar occultation for ice experiment, J. Atmos. Solar-Terr. Phys., 71, 300-315, doi:10.1016/j.jastp.2008.07.012, 2009.

Gray, L. J. and Russell Jr., J. M.: Interannual variability of trace gases in the subtropical winter stratosphere, J. Atmos. Sci., 56, 977-993, 1999.

Hammer, S., Glatzel-Mattheier, H., Müller, L., Sabasch, M., Schmidt, M., Schmitt, S., Schönherr, C., Vogel, F., Worthy, D. E., and Levin, I.: A gas chromatographic system for high-precision quasi-continuous atmospheric measurements of $\mathrm{CO}_{2}, \mathrm{CH}_{4}, \mathrm{~N}_{2} \mathrm{O}, \mathrm{SF}_{6}, \mathrm{CO}$ and $\mathrm{H}_{2}$, available at: http://www.iup.uni-heidelberg.de/institut/forschung/groups/ kk/GC_Hammer_25_SEP_2008.pdf (last access: 15 November 2015), 2008.

Kiefer, M., Aubertin, G., Birk, M., De Laurentis, M., Eckert, E., Kleinert, A., Perron, G., and Wagner, G.: Impact of Improved Corrections for MIPAS Detector Non-Linearity, in: Atmospheric Composition Validation and Evolution, Frascati, 13-15 March 2013, Abstract Book, p. 38, ESA, 2013.

Laeng, A., Hubert, D., Verhoelst, T., von Clarmann, T., Dinelli, B. M., Dudhia, A., Raspollini, P., Stiller, G., Grabowski, U., Keppens, A., Kiefer, M., Sofieva, V., Froidevaux, L., Walker, K. A., Lambert, J.-C., and Zehner, C.: The Ozone
Climate Change Initiative: Comparison of four Level-2 Processors for the Michelson Interferometer for Passive Atmospheric Sounding (MIPAS), Remote Sens. Environ., 162, 316343, doi:10.1016/j.rse.2014.12.013, 2015.

Levin, I., Glatzel-Mattheier, H., Marik, T., Cuntz, M., Schmidt, M., and Worthy, D. E.: Verification of German methane emission inventories and their recent changes based on atmospheric observations, J. Geophys. Res., 104, 3447-3456, 1999.

National Oceanic and Atmospheric Administration (NOAA) Global Greenhouse Gas Reference Network: Figures, available at: http:// www.esrl.noaa.gov/gmd/ccgg/figures/, last access: 15 November 2015.

Network for the Detection of Atmospheric Composition Change (NDACC) Satellite Working Group: Trace gases measured by atmospheric sensors, available at: http://accsatellites.aeronomie. be/index.php/measured-trace-gases (last access: 6 February 2013), 2008.

Noël, S., Bramstedt, K., Rozanov, A., Bovensmann, H., and Burrows, J. P.: Stratospheric methane profiles from SCIAMACHY solar occultation measurements derived with onion peeling DOAS, Atmos. Meas. Tech., 4, 2567-2577, doi:10.5194/amt-42567-2011, 2011.

Park, J. H., Russell III, J. M., Gordley, L. L., Drayson, S. R., Benner, D. C., McInerney, J. M., Gunson, M. R., Toon, G. C., Sen, B., Blavier, J.-F., Webster, C. R., Zipf, E. C., Erdman, P., Schmidt, U., and Schiller, C.: Validation of Halogen Occultation Experiment $\mathrm{CH}_{4}$ measurements from the UARS, J. Geophys. Res., 101, 10183-10203, 1996.

Payan, S., Camy-Peyret, C., Oelhaf, H., Wetzel, G., Maucher, G., Keim, C., Pirre, M., Huret, N., Engel, A., Volk, M. C., Kuellmann, H., Kuttippurath, J., Cortesi, U., Bianchini, G., Mencaraglia, F., Raspollini, P., Redaelli, G., Vigouroux, C., De Mazière, M., Mikuteit, S., Blumenstock, T., Velazco, V., Notholt, J., Mahieu, E., Duchatelet, P., Smale, D., Wood, S., Jones, N., Piccolo, C., Payne, V., Bracher, A., Glatthor, N., Stiller, G., Grunow, K., Jeseck, P., Te, Y., and Butz, A.: Validation of version-4.61 methane and nitrous oxide observed by MIPAS, Atmos. Chem. Phys., 9, 413-442, doi:10.5194/acp-9-413-2009, 2009.

Randel, W. J., Wu, F., Russell III, J. M., Roche, A., and Waters, J. W.: Seasonal cycles and QBO variations in stratospheric $\mathrm{CH}_{4}$ and $\mathrm{H}_{2} \mathrm{O}$ observed in UARS HALOE data, J. Atmos. Sci., 55, 163-185, 1998.

Randel, W. J., Wu, F., Russell III, J. M., and Waters, J.: Spacetime patterns of trends in stratospheric constituents derived from UARS measurements, J. Geophys. Res., 104, 3711-3727, 1999.

Raspollini, P., Arnone, E., Barbara, F., Carli, B., Castelli, E., Ceccherini, S., Dinelli, B. M., Dudhia, A., Kiefer, M., Papandrea, E., and Ridolfi, M.: Comparison of the MIPAS products obtained by four different level 2 processors, Annals of Geophysics, 56, doi:10.4401/ag-6338, 2014.

Rodgers, C. D. and Connor, B. J.: Intercomparison of remote sounding instruments, in: Optical Remote Sensing of the Atmosphere, OSA Technical Digest, 46-48, Optical Society of America, Washington DC, 1999, 1999.

Russell III, J. M., Gordley, L. L., Park, J. H., Drayson, S. R., Hesketh, W. D., Cicerone, R. J., Tuck, A. F., Frederick, J. E., Harries, J. E., and Crutzen, P. J.: The Halogen Occultation Experiment, J. Geophys. Res., 98, 10777-10797, 1993. 
Ruth, S., Kennaugh, R., Gray, L. J., and Russell III, J. M.: Seasonal, semiannual, and interannual variability seen in measurements of methane mady by the UARS Halogen Occultation Experiment, J. Geophys. Res., 102, 16189-16199, 1997.

Shu, J., Tian, W., Hu, D., Zhang, J., Shang, L., Tian, H., and Xie, F.: Effects of the quasi-biennial oscillation and stratospheric semiannual oscillation on tracer transport in the upper stratosphere, J. Atmos. Sci., 70, 1370-1389, doi:10.1175/JAS-D-12053.1, 2013.

Sofieva, V. F., Tamminen, J., Kyrölä, E., Laeng, A., von Clarmann, T., Dalaudier, F., Hauchecorne, A., Bertaux, J.-L., Barrot, G., Blanot, L., Fussen, D., and Vanhellemont, F.: Validation of GOMOS ozone precision estimates in the stratosphere, Atmos. Meas. Tech., 7, 2147-2158, doi:10.5194/amt-7-2147-2014, 2014.

Stiller, G. P., Kiefer, M., Eckert, E., von Clarmann, T., Kellmann, S., García-Comas, M., Funke, B., Leblanc, T., Fetzer, E., Froidevaux, L., Gomez, M., Hall, E., Hurst, D., Jordan, A., Kämpfer, N., Lambert, A., McDermid, I. S., McGee, T., Miloshevich, L., Nedoluha, G., Read, W., Schneider, M., Schwartz, M., Straub, C., Toon, G., Twigg, L. W., Walker, K., and Whiteman, D. N.: Validation of MIPAS IMK/IAA temperature, water vapor, and ozone profiles with MOHAVE-2009 campaign measurements, Atmos. Meas. Tech., 5, 289-320, doi:10.5194/amt-5-289-2012, 2012.

Toon, G. C.: The JPL MkIV Interferometer, Opt. Photonics News, 2, 19-21, 1991.

Toon, G. C., Blavier, J.-F., Sen, B., Margitan, J. J., Webster, C. R., May, R. D., Fahey, D., Gao, R., DelNegro, L., Proffitt, M., Elkins, J., Romashkin, P. A., Hurst, D. F., Oltmans, S., Atlas, E., Schauffler, S., Flocke, F., Bui, T. P., Stimpfle, R. M., Bonne, G. P., Voss, P. B., and Cohen, R. C.: Comparison of MkIV balloon and ER2 aircraft measurements of atmospheric trace gases, J. Geophys. Res., 104, 26779-26790, 1999. von Clarmann, T.: Validation of remotely sensed profiles of atmospheric state variables: strategies and terminology, Atmos. Chem. Phys., 6, 4311-4320, doi:10.5194/acp-6-4311-2006, 2006.

von Clarmann, T., Glatthor, N., Grabowski, U., Höpfner, M., Kellmann, S., Kiefer, M., Linden, A., Mengistu Tsidu, G., Milz, M., Steck, T., Stiller, G. P., Wang, D. Y., Fischer, H., Funke, B., Gil-López, S., and López-Puertas, M.: Retrieval of temperature and tangent altitude pointing from limb emission spectra recorded from space by the Michelson Interferometer for Passive Atmospheric Sounding (MIPAS), J. Geophys. Res., 108, 4736, doi:10.1029/2003JD003602, 2003.

von Clarmann, T., De Clercq, C., Ridolfi, M., Höpfner, M., and Lambert, J.-C.: The horizontal resolution of MIPAS, Atmos. Meas. Tech., 2, 47-54, doi:10.5194/amt-2-47-2009, 2009a.

von Clarmann, T., Höpfner, M., Kellmann, S., Linden, A., Chauhan, S., Funke, B., Grabowski, U., Glatthor, N., Kiefer, M., Schieferdecker, T., Stiller, G. P., and Versick, S.: Retrieval of temperature, $\mathrm{H}_{2} \mathrm{O}, \mathrm{O}_{3}, \mathrm{HNO}_{3}, \mathrm{CH}_{4}, \mathrm{~N}_{2} \mathrm{O}, \mathrm{ClONO}_{2}$ and $\mathrm{ClO}$ from MIPAS reduced resolution nominal mode limb emission measurements, Atmos. Meas. Tech., 2, 159-175, doi:10.5194/amt-2-159-2009, 2009b.

von Clarmann, T., Stiller, G., Grabowski, U., Eckert, E., and Orphal, J.: Technical Note: Trend estimation from irregularly sampled, correlated data, Atmos. Chem. Phys., 10, 6737-6747, doi:10.5194/acp-10-6737-2010, 2010.

Waymark, C., Walker, K. A., Boone, C. D., and Bernath, P. F.: ACEFTS version 3.0 data set: validation and data processing update, Annals of Geophysics, 56, doi:10.4401/ag-6339, 2013.

Youn, D., Choi, W., Lee, H., and Wuebbles, D. J.: Interhemispheric differences in changes of long-lived tracers in the middle stratosphere over the last decade, Geophys. Res. Lett., 33, L03807, doi:10.1029/2005GL024274, 2006. 